\title{
QUALIDADE DAS ÁGUAS DOS CÓRREGOS SÃO JOAQUIM E RIBEIRÃO CLARO, BACIA DO RIO CORUMBATAÍ, SP, BRASIL.
}

\section{WATER QUALITY EVALUATION ON SÃO JOAQUIM AND RIBEIRÃO CLARO STREAM, MICROBASIN OF CORUMBATAI RIVER, SÃO PAULO, STATE, BRAZIL.}

\section{Gertel, P., Tauk-Tornisielo, S.M.; Malagutti, E.N.}

Centro de Estudos Ambientais da Universidade Estadual Paulista (UNESP) - Campus de Rio Claro/SP

\section{RESUMO}

A água é um recurso natural finito e indispensável para todo organismo vivente. Por isso é fundamental assegurar seu uso e manutenção nos ecossistemas. Dada a esta importância, foram desenvolvidos estudos sobre a qualidade das águas dos córregos São Joaquim e Ribeirão Claro, ambos pertencentes à bacia do rio Corumbataí, entre as latitudes $22^{\circ} 36^{\prime} \mathrm{S}$ e $22^{\circ} 16^{\prime} \mathrm{S}$ e as longitudes $46^{\circ} 36^{\prime} \mathrm{W}$ e $47^{\circ} 26^{\prime} \mathrm{W}$. Nesta microbacia foram verificados os aspectos climáticos, geomorfológicos, geológicos e sócio-demográficos. Foram definidos cinco pontos de coletas, sendo dois deles no Ribeirão Claro e três no córrego São Joaquim. As coletas mensais foram realizadas no período de seis meses, entre abril e setembro, correspondendo à época de seca com temperaturas mais baixas. As amostras de água foram coletadas na metade do corte transversal da calha principal do rio, a $20 \mathrm{~cm}$ de profundidade em relação à superfície da água. Foram avaliadas as variáveis físico-químicas, químicas, físicas e biológicas, no total de 16 parâmetros e os resultados foram submetidos as análises estatísticas. Segundo a Resolução CONAMA 20/86, os dados demonstraram que as águas do córrego São Joaquim se enquadram na Classe 2, excetuando os valores de oxigênio dissolvido, coliformes totais e Escherichia coli, que se encontraram acima do limite definido para a Classe 3, por esta mesma Resolução. Quanto ao Ribeirão Claro, no trecho estudado, pode ser enquadrado na Classe 4, mesmo quando desemboca no rio Corumbataí. Observou-se que a poluição dessas águas provém do lançamento de esgoto urbano in natura. 
Palavras-chaves: impactos ambientais, qualidade da água, córregos São Joaquim e Ribeirão Claro.

\section{ABSTRACT}

The water is a finite natural resource, and indispensable for all organism which made its conservation and management an priority issue for ecosystems maintenance.Given to this importance, several studies were developed on the waters quality of São Joaquim and Ribeirão Claro streams, belonging to Corumbataí river basin, located between the latitudes $22^{\circ} 36^{\prime} \mathrm{S}$ and $22^{\circ} 16^{\prime} \mathrm{S}$ and longitudes $46^{\circ} 36^{\prime} \mathrm{W}$ and $47^{\circ} 26^{\prime} \mathrm{W}$. In this microbasin, were verified climatic geomorphologic, geological and socialdemographic parameters. It was defined 5 collection points, being 2 in the Ribeirão Claro and 3 in the São Joaquim stream. The monthly collections were developed, between April and September/2002, when the weather is characterized by lower temperatures. The water samples were collected in the middle of the traversal water course at $20 \mathrm{~cm}$ deep of the water surface. Were evaluated physical-chemical, chemical, physical and biological were variables, in the total of 16 parameters and the results were submitted to statistical analysis. According to the CONAMA 20/86 Resolution the data showed that the waters of São Joaquim stream belongs to Class 2, excepting for the values of dissolved oxygen, total coliformes, and Escherichia coli, which are above to the limit defined for the Class 3.The Ribeirão Claro stream, situated in the studied area, however, can be inserted in the Class 4 , despite of its flow into the Corumbataí river. It was observed that the pollution of those waters comes from the release of urban sewer in natura.

Keywords: environmental impacts, water quality, São Joaquim and Ribeirão Claro stream.

\section{INTRODUÇÃO}

A água é um recurso natural renovável de origem mineral. Dos 1400 milhões de $\mathrm{km}^{3}$ de água estimados no planeta, somente 40 milhões de $\mathrm{km}^{3}$ (correspondente a $3 \%$ do total) são de água doce. Desses, $77,2 \%$ correspondem às calotas polares e glaciares; $22,4 \%$ são de águas subterrâneas; $0,35 \%$ são lagos e pântanos; $0,04 \%$ estão na atmosfera e somente $0,01 \%$ estão nos rios (CUNHA et al., 1980). Poucos pesquisadores têm dedicado sua atenção à origem, às propriedades peculiares e à distribuição da água. Este recurso, talvez por ser muito abundante principalmente no Brasil, se tornou tão "banal" que sua presença, embora indispensável, não chamou muito a atenção em anos anteriores (BRANCO, 1993).

Lloyd (1989) citado por Palma-Silva (1999) concluiu que apenas $40 \%$ da 
população dos países em desenvolvimento têm água adequada para consumo. Como exemplo, na região sudeste do Brasil onde vem ocorrendo crescimento demográfico e econômico acelerados, haverá no futuro um comprometimento da qualidade e quantidade dos recursos hídricos, principalmente devido ao crescimento desordenado de seus centros urbanos.

Já na década de 90, foi constatado que toda a bacia do rio Piracicaba, onde localiza-se o rio Corumbataí e seus afluentes (NEGRI, 1992) que as perspectivas decorrentes dos crescimentos econômicos e populacional acentuados e contínuos seria a incrementação da demanda da água e também das descargas poluidoras remanescentes, configurando-se em um quadro preocupante para essa região.

Dentro da bacia do rio Corumbataí, onde situam-se os dois córregos aqui estudados, vem ocorrendo um desenvolvimento acelerado da atividade produtora de cerâmicas, que segundo Batalha e Parlatore (1977), resulta na perda da qualidade de vida das populações circunvizinhas. Ferreira (2000) verificou a presença de grandes quantidades de metais tóxicos nos materiais utilizados por essa atividade, que além de comprometer o solo e o ar, também vem afetando a qualidade das águas. Existe sérios problemas resultantes de metais de água nos corpos de água desta região.

Considerando-se o amplo desenvolvimento dessa atividade industrial além de outras, somando-se ao intenso cultivo de cana-de-açúcar e cítricos, além do acelerado desenvolvimento urbano na bacia do rio Corumbataí, torna-se necessário um constante da qualidade ambiental, juntamente com medidas mitigadoras para uma definição de um planejamento ambiental eficaz, visando a conservação ambiental desta área.

No intuito de colaborar com subsídios necessários para este planejamento, procurou-se verificar a qualidade das águas e impactos ambientais negativos no córrego São Joaquim e um trecho do Ribeirão Claro, ambos pertencentes a bacia do rio Corumbataí, Estado de São Paulo.

\section{MATERIAIS E MÉTODOS}

\section{Características gerais da área de estudo}

A Política de Recursos Hídricos de acordo com a Lei Estadual $n^{\circ} 7663$ de dezembro de 1991 instituiu no Estado de São Paulo 22 Unidades de Gerenciamentos de Recursos Hídricos (UGRHIs). A sub-bacia do Ribeirão Claro (UGRHI 5) situa-se na região central do Estado de São Paulo dentro da bacia do rio Corumbataí, abrangendo os municípios de Araras, Corumbataí, Rio Claro e Santa Gertrudes, (latitudes de $22^{\circ} 36^{\prime} \mathrm{S}$ e 
$22^{\circ} 16^{\prime} \mathrm{S}$ e longitudes de $46^{\circ} 36^{\prime} \mathrm{W}$ e $47^{\circ} 26^{\prime} \mathrm{W}$ ). Esta sub-bacia apresenta $13,98 \mathrm{~km}$ de largura por $34,04 \mathrm{~km}$ de comprimento e sua drenagem ocupa a extensão de $270 \mathrm{~km}^{2}$, com nascentes no município de Corumbataí-SP (RODRIGUES, 1997).

Segundo a classificação de Köppen, o clima da região é do tipo Cwa (w: seco no inverno; a: mês mais quente com temperatura superior a $22^{\circ} \mathrm{C}$ ), ou seja, clima tropical chuvoso, com chuvas de verão. A quantidade média de chuvas é de 1.250 $\mathrm{mm} . \mathrm{ano}^{-1}$, sendo o período mais chuvoso, entre os meses de outubro e março e o período mais seco, de abril a setembro. A temperatura média anual é de $20,3{ }^{\circ} \mathrm{C}$ (BRINO, 1985).

A área de estudo situa-se no setor ocidental da "Depressão Periférica Paulista", Zona do Médio Tietê (CHRISTOFOLETTI, 1999). A região é pouco acidentada, predominando colinas baixas, suaves e convexas. De acordo com a Carta Geográfica do Estado de São Paulo (IPT, 1981), o solo da região apresenta média suscetibilidade à processos de colapso ou expansão/contração do solo e suas características contribuem para a qualidade das águas da região. Entre outras, citam-se o fato desta área estar localizada no flanco nordeste da Bacia Sedimentar do Paraná (LIMA, 2000). Seu material argiloso é bastante friável e os sedimentos pertencem à Formação Corumbataí. O material de cobertura, com exceção dos $0,10 \mathrm{~m}$ de solo orgânico, é caracterizado por solo argiloso com espessura variável (THOMAZELLA, 1999).

A Pedologia da bacia do Ribeirão Claro (OLIVEIRA, 1981 citado por BRAGA,1997), identifica as seguintes classes de solos: areias quartzosas profundas são encontradas próximo à nascente do Ribeirão Claro; na zona urbana ocorre latossolo vermelho amarelo, desde o centro-norte até o sudeste; sendo os solos mais abundantes com profundidades de $1,5 \mathrm{~m}$ a $2,5 \mathrm{~m}$, os podzólicos vermelho amarelo.

Entre os fatores antrópicos da bacia do Ribeirão Claro, estão: o lançamento de esgotos "in natura" e dejetos urbanos, como os resíduos de marmorearia e avícola, indústrias cerâmicas e de cosméticos, localizadas às margens do Ribeirão Claro, a médio curso e à jusante da cidade de Rio Claro (CUNHA, 2000).

\section{Pontos de coleta}

Foram estabelecidos dois pontos no Ribeirão Claro, ambos à jusante da cidade de Rio Claro: o ponto 1 (P1) antes da foz do Córrego São Joaquim e o ponto 5 (P5), antes de sua foz a 2,5km da saída da rodovia SP 127, no km 3. Outros três pontos de coleta foram no Córrego São Joaquim, o ponto 2 (P2) à montante da cidade de Santa Gertrudes; ponto 4 (P4) antes da foz no Ribeirão Claro, à jusante de Santa Gertrudes; e o ponto 3 (P3) no córrego do Barreiro, à montante da cidade de Santa Gertrudes (Figura1) 


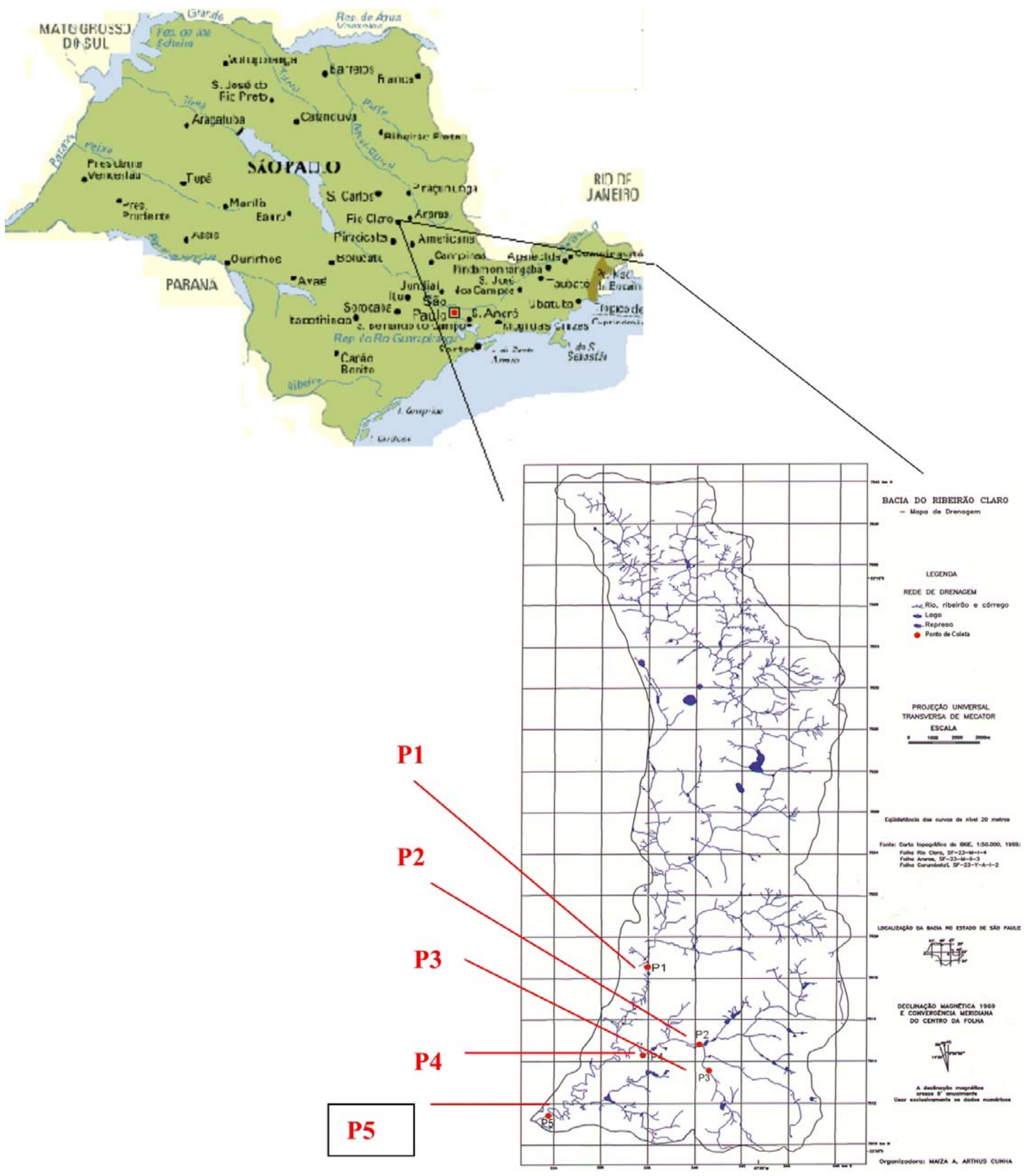

Figura 1 - Localização dos pontos de coleta das amostras de água no Ribeirão Claro, no córrego São Joaquim e no córrego do Barreiro. Fonte: alterado de Cunha, 2000. 


\section{Metodologia das coletas das águas}

Coletas mensais ocorreram entre abril e setembro 2002, sempre na primeira semana do mês, no período da manhã entre 8:00 e 11:00 horas. Foram coletadas duas amostras em cada ponto, na metade do corte transversal da calha principal do rio, aproximadamente a $20 \mathrm{~cm}$ da superfície da água, utilizando-se coletores construídos (CETESB, 1987), ou com amostrador de Van Dorn. As amostras foram acondicionadas em frascos de polietileno de $1 \mathrm{~L}$. Para armazenar as águas para as análises de coliformes totais e fecais, foram utilizados frascos de $250 \mathrm{~mL}$ previamente esterilizados, devidamente fechados, sendo a tampa envolvida com papel protetor.

As análises dos fatores abióticos foram realizadas no mesmo dia no dia seguinte da coleta, com exceção das análises do nitrogênio orgânico total, que foram efetuadas, no máximo, até uma semana após a coleta. As amostras foram mantidas a $4^{\circ} \mathrm{C}$. Para temperatura da água, condutividade elétrica, sólidos totais dissolvidos, turbidez, fósforo total, alcalinidade, salinidade e cor aparente, foram realizadas duas análises por ponto de coleta. A demanda química de oxigênio (DQO) foi analisada quatro vezes por ponto de coleta.

A temperatura do ar $\left({ }^{\circ} \mathrm{C}\right)$ foi determinada em termômetro digital, marca Precision, com precisão de $\pm 0,1^{\circ} \mathrm{C}$. Os valores de $\mathrm{pH}$ foram determinados com aparelho de campo, marca Mettler Toledo, precisão $\pm 0,02$. A temperatura da água $\left({ }^{\circ} \mathrm{C}\right)$, condutividade elétrica $\left(\mathrm{m} \mathrm{S} \cdot \mathrm{cm}^{-1}\right)$, sólidos totais dissolvidos (STD) $\left(\mathrm{mg} \cdot \mathrm{L}^{-1}\right)$ e turbidez (UNT) foram determinadas com leituras diretas no aparelho de campo Hach, com precisão de $\pm 1,0^{\circ} \mathrm{C}$.

Os valores da alcalinidade foram determinados através do método da titulação potenciométrica (GOLTERMAN et al., 1978) e do oxigênio dissolvido através do método titulométrico de Winkler, modificado com adição de azida sódica (GOLTERMAN et al., 1978). O método utilizado para fósforo total ( $\mathrm{m} \mathrm{g} \cdot \mathrm{L}-1)$ foi descrito por Golterman et al. (1978) e para o nitrogênio orgânico total $\left(\mathrm{mg} \cdot \mathrm{L}^{-1}\right)$ por Mackereth et al. (1978). A determinação da cor aparente (PtCo) foi realizada no espectrofotômetro marca Hach, com precisão de $\pm 10 \%$. A DQO $\left(\mathrm{mg} \cdot \mathrm{L}^{-1}\right)$ foi verificada através da digestão ácida com dicromato de potássio, aprovada pela USEPA (U.S. Envirommental Protection Agency), em reator de digestão marca Hach, modelo COD REACTOR e espectrofotômetro da mesma marca, modelo DR/2000, com precisão de $\pm 1 \mathrm{mg}$. $\mathrm{L}^{-1}$. As medidas de sólidos suspensos totais $\left(\mathrm{mg} \cdot \mathrm{L}^{-1}\right)$ foram realizadas com filtragem em filtro millipore, posteriormente submetidos à secagem por 2 horas, a $105^{\circ} \mathrm{C}$, para posterior pesagem em balança analítica. A salinidade (\%o) foi determinada com aparelho de campo, marca Hach, precisão de $\pm 0,1 \%$. 
A determinação dos números mais prováveis (NMP) de coliformes totais e Escherichia coli foi realizada com substrato definido (Defined Substrate Tecnology DST), utilizado para detecções simultâneas, identificações específicas e confirmativas desses microrganismos em água. A técnica de Colilert (sistema patenteado por IDEXX Laboratories, Inc. Westbook, ME) é baseada na tecnologia da DST, onde são utilizados nutrientes indicadores (EATON et al., 1995). Com o uso do Colilert, elimina-se a interferência de bactérias heterotróficas e crescimento confluentes. A demanda bioquímica de oxigênio $\left(\mathrm{DBO}_{5}\right)\left(\mathrm{mgO}_{2} \cdot \mathrm{L}^{-1}\right)$ foi determinada nas amostras incubadas durante cinco dias, a $20 \pm 5^{\circ} \mathrm{C}$. O método foi o Iodométrico ou Winkler modificado devido a adição de azida sódica (NOUR, 1994).

\section{Análise estatística e interpretação dos dados obtidos}

Foi realizada análise estatística através da técnica de variância pelo teste de Friedman para comparar as variáveis químicas, físicas, físico-químicas e biológicas nos diferentes pontos de coleta, com a utilização do software Bioestat 2 (AYRES et al., 2000).

\section{RESULTADOS E DISCUSSÃO}

Após as análises do mapa de uso e ocupação do solo que mostraram boa conservação e proteção das matas ciliares, áreas reflorestadas da atual Floresta "Navarro de Andrade" e da mata natural da Fazenda São José, (à montante e médio curso) do Ribeirão Claro, foram realizadas muitas excursões na área estudada. Nestas pode-se observar uma maior degradação das matas ciliares no médio curso do Ribeirão Claro, à jusante da foz. Existem grandes influências das ampliações das áreas urbanas sobre as matas ciliares, na drenagem principal e dos tributários da região. Verificou-se predomínio do cultivo de cana-de-açúcar e de áreas de pastagens desocupadas em toda região, sendo que estas últimas situam-se mais às margens do Ribeirão Claro, ao sul de sua sub-bacia.

Os valores máximo e mínimos dos parâmetros físicos, químicos e físicoquímicos medidos na área e no período deste estudo estão na tabela 1. Como a amplitude temporal deste estudo não abrangeu todos os meses do ano, não se pode afirmar que este parâmetro sofreu variação sazonal, apesar da tendência constatada de seus valores. Acrescenta-se que as amostras realizadas corresponderam ao período seco e frio da região. Os valores de temperatura do ar foram analisados estatisticamente, em nível de $5 \%$, apresentando igualdade estatisticamente significativa entre os pontos de coleta (Tabela 2). 
Em relação aos valores das temperaturas da água (Tabela 2), em nível de 5\%, ocorreu igualdade estatisticamente significativa entre os pontos de coleta. Estas temperaturas desempenham principal papel no controle no meio aquático, condicionando as influências de uma série de parâmetros abióticos do sistema. A temperatura superficial é influenciada por fatores como latitude, altitude, estação do ano, período do dia, taxa de fluxo e profundidade (CETESB, 2001).

Tabela 1. Valores mínimos e máximos dos parâmetros físicos, químicos e físicoquímicos determinados nos diferentes pontos de coleta, no período de abr/2002 a set/2002.

\begin{tabular}{|c|c|c|c|c|c|}
\hline Parâmetros & P1 & $\begin{array}{c}\text { Pontos } \\
\text { P2 }\end{array}$ & $\begin{array}{l}\text { de } \\
\text { P3 }\end{array}$ & $\begin{array}{c}\text { Coletas } \\
\text { P4 }\end{array}$ & P5 \\
\hline $\begin{array}{c}\text { Temperatura do ar } \\
\left({ }^{\circ} \mathrm{C}\right)\end{array}$ & $15,5-27,4$ & $15,4-28,1$ & $\begin{array}{l}18,5- \\
26,4\end{array}$ & $\begin{array}{l}18,9- \\
25,6\end{array}$ & $17,9-31,9$ \\
\hline $\begin{array}{l}\text { Temperatura da } \\
\text { água }\left({ }^{\circ} \mathrm{C}\right)\end{array}$ & $16,4-23,5$ & $15,5-23,2$ & $\begin{array}{l}16,5- \\
22,5\end{array}$ & $\begin{array}{l}15,1- \\
23,5\end{array}$ & $15,5-24,6$ \\
\hline $\mathrm{PH}$ & $7,5-8,0$ & $7,0-8,5$ & $6,9-8,2$ & $6,8-7,7$ & $7,0-7,7$ \\
\hline $\begin{array}{l}\text { Condutividade } \\
\text { elétrica }\left(\mu \mathrm{S} \cdot \mathrm{cm}^{-1}\right)\end{array}$ & $\begin{array}{l}115,4- \\
378,5\end{array}$ & $34,6-95,6$ & $\begin{array}{l}56,3- \\
77,4\end{array}$ & $\begin{array}{l}97,4- \\
116,0\end{array}$ & $\begin{array}{l}103,4- \\
233,5\end{array}$ \\
\hline $\begin{array}{c}\text { Sólidos totais } \\
\text { dissolvidos }\left(\mathrm{mg} \cdot \mathrm{L}^{-1}\right)\end{array}$ & $\begin{array}{l}54,5- \\
180,0\end{array}$ & $28,0-46,5$ & $\begin{array}{l}25,0- \\
37,0\end{array}$ & $\begin{array}{l}46,0- \\
55,0\end{array}$ & $\begin{array}{l}47,0- \\
111,0\end{array}$ \\
\hline Turbidez (UNT) & $17,7-37,4$ & $21,4-45,0$ & $\begin{array}{l}11,7- \\
33,9\end{array}$ & $\begin{array}{l}19,0- \\
203,5\end{array}$ & $14,4-74,9$ \\
\hline $\begin{array}{c}\text { Alcalinidade }\left(\mathrm{mg} \cdot \mathrm{L}^{-}\right. \\
1)\end{array}$ & $39,3-64,1$ & $30,3-41,2$ & $\begin{array}{l}30,3- \\
40,1\end{array}$ & $\begin{array}{c}44,8- \\
57,8\end{array}$ & $44,7-66,8$ \\
\hline $\begin{array}{l}\text { Oxigênio dissolvido } \\
\left(\mathrm{mg} \cdot \mathrm{L}^{-1}\right)\end{array}$ & $0,7-4,0$ & $6,6-8,5$ & $5,1-9,3$ & $0,6-4,6$ & $5,2-7,6$ \\
\hline $\begin{array}{l}\text { Fósforo total }\left(\mathrm{mg} \cdot \mathrm{L}^{-}\right. \\
1)\end{array}$ & $0,2-0,4$ & $0,0-0,3$ & $0,0-0,1$ & $0,2-0,4$ & $0,2-0,4$ \\
\hline $\begin{array}{l}\text { Nitrogênio orgânico } \\
\quad \text { total }\left(\mathrm{mg} \cdot \mathrm{L}^{-1}\right)\end{array}$ & $2,4-8,8$ & $1,2-6,1$ & $0,9-2,8$ & $3,2-7,3$ & $2,8-11,2$ \\
\hline
\end{tabular}




\begin{tabular}{||c||c||c||c||c||c||} 
Cor aparente $(\mathrm{PtCo})$ & $120,5-$ & $117,5-$ & $73,5-$ & $77,5-$ & $27,5-$ \\
245,0 & 348,0 & 300,5 & 313,5 & 492,0 \\
\hline \hline DQO $\left(\mathrm{mg} \cdot \mathrm{L}^{-1}\right)$ & $16,3-63,2$ & $7,3-48,0$ & $\begin{array}{c}14,3- \\
54,0\end{array}$ & $\begin{array}{c}15,0- \\
57,2\end{array}$ & $8,7-74,2$ \\
\hline \hline $\begin{array}{c}\text { Sólidos em } \\
\text { suspensão totais } \\
\left(\mathrm{mg} \cdot \mathrm{L}^{-1}\right)\end{array}$ & nd-0,9 & nd-0,2 & nd-0,2 & nd-0,1 & nd-0,1 \\
\hline \hline Salinidade $(\%)$ & $0,1-0,2$ & $0,0-0,0$ & $0,0-0,0$ & $0,0-0,1$ & $0,0-0,1$ \\
\hline \hline
\end{tabular}

Os resultados dos valores de $\mathrm{pH}$ (Tabela 1) quando analisados estatisticamente em nível de 5\%, tiveram igualdade estatisticamente significativa entre os pontos de coletas (Tabela 2). $\mathrm{O} \mathrm{pH}$ atua sobre os organismos aquáticos que estão adaptados às condições de neutralidade. As alterações bruscas do $\mathrm{pH}$ podem acarretar o desaparecimento de determinados organismos aquáticos que são mais sensíveis a tais mudanças. Valores fora das faixas recomendadas podem alterar o sabor da água e contribuir para a corrosão do sistema de distribuição, como uma possível extração do ferro, cobre, chumbo, zinco e cádmio, e dificultar a descontaminação das águas (CETESB, 2001). A Resolução CONAMA 20/86 estabelece para os corpos hídricos de água doce que as classes 1,2 e 3, o pH deve estar entre os limites de 6,0 e 9,0. Os valores de $\mathrm{pH}$ encontrados ficaram dentro dos limites estabelecidos para as classes 1,2 e 3 .

Os valores máximos e mínimos da condutividade elétrica estão na tabela 1. Os menores valores deste parâmetro ocorreram nos pontos de coleta P2 e P3. Este parâmetro corresponde à capacidade da água em conduzir corrente elétrica e está relacionado com a presença de íons dissolvidos e a temperatura.

Tabela 2. Análise estatística usando os testes de Friedman $(\mathrm{a}=5 \%)$ e de comparações múltiplas, Bioestat 2, dos resultados dos diferentes parâmetros determinados nas águas dos pontos de coleta estudados, nos córregos São Joaquim e Ribeirão Claro, no período de no período de abr/2002 a set/2002.

\begin{tabular}{|c|c|c|c|c|c|c|c|c|c|c|}
\hline \multirow[t]{3}{*}{ Parâmetros } & \multicolumn{10}{|c|}{ PONTOS DE COLETA } \\
\hline & \multicolumn{2}{|c|}{$\mathbf{P 1}$} & \multicolumn{2}{|c|}{$\mathbf{P 2}$} & \multicolumn{2}{|c|}{ P3 } & \multicolumn{2}{|c|}{$\mathbf{P 4}$} & \multicolumn{2}{|c|}{ P5 } \\
\hline & $\mathbf{a}$ & b & $\mathbf{a}$ & b & $\mathbf{a}$ & b & $\mathbf{a}$ & b & $\mathbf{a}$ & b \\
\hline
\end{tabular}




\begin{tabular}{|c|c|c|c|c|c|c|c|c|c|c|}
\hline $\begin{array}{l}\text { Temperatura } \\
\text { do ar }\end{array}$ & 2,0 & A & 2,5 & A & 3,2 & A & 3,5 & A & 3,9 & A \\
\hline $\begin{array}{l}\text { Temperatura } \\
\text { da água }\end{array}$ & 3,5 & A & 3,2 & A & 2,8 & A & 2,7 & A & 2,7 & A \\
\hline PH & 3,9 & A & 3,1 & A & 3,1 & A & 3,1 & A & 1,8 & $\mathrm{~A}$ \\
\hline \begin{tabular}{|l|} 
Condutividade \\
elétrica
\end{tabular} & 4,7 & A & 1,5 & B & 1,5 & B & 3,0 & A B & 4,3 & A \\
\hline $\begin{array}{c}\text { Sólidos } \\
\text { totais } \\
\text { dissolvidos }\end{array}$ & 4,7 & A & 1,6 & B & 1,4 & B & 3,0 & A B & 4,3 & A \\
\hline Turbidez & 2,2 & A B & 4,3 & A & 1,6 & B & 4,4 & A & 2,4 & $\begin{array}{l}\text { A } \\
\text { B }\end{array}$ \\
\hline Alcalinidade & 4,0 & A B & 1,4 & $\mathrm{C}$ & 1,6 & B C & 3,6 & A B C & 4,4 & $\mathrm{~A}$ \\
\hline $\begin{array}{c}\text { Oxigênio } \\
\text { dissolvido }\end{array}$ & 1,3 & $\mathrm{~B}$ & 4,4 & A & 4,4 & A & 1,7 & B & 3,2 & $\begin{array}{l}\text { A } \\
\text { B }\end{array}$ \\
\hline Fósforo total & 3,8 & A & 2,4 & A B & 1,1 & $\mathrm{~B}$ & 3,8 & A & 3,8 & $\mathrm{~B}$ \\
\hline $\begin{array}{c}\text { Nitrogênio } \\
\text { orgânico } \\
\text { total }\end{array}$ & 4,2 & $\mathrm{~A}$ & 2,1 & $\mathrm{AB}$ & 1,2 & B & 3,5 & $\mathrm{AB}$ & 4,0 & $\mathrm{~A}$ \\
\hline $\begin{array}{c}\text { Cor } \\
\text { aparente } \\
\end{array}$ & 2,8 & $\mathrm{~A}$ & 3,5 & A & 2,7 & A & 3,8 & A & 2,2 & A \\
\hline DQO & 3,7 & A B & 1,2 & $\mathrm{~B}$ & 2,5 & A B & 3,6 & A B & 4,0 & $\mathrm{~A}$ \\
\hline $\begin{array}{c}\text { Sólidos } \\
\text { totais em } \\
\text { suspensão }\end{array}$ & 3,2 & $\mathrm{~A}$ & 3,2 & A & 3,2 & A & 2,7 & A & 2,8 & $\mathrm{~A}$ \\
\hline Salinidade & 3,0 & A & 3,0 & A & 3,0 & A & 3,0 & A & 3,0 & $\mathrm{~A}$ \\
\hline $\begin{array}{c}\text { Coliformes } \\
\text { totais }\end{array}$ & 4,2 & A & 3,7 & A B & 3,7 & A B & 2,3 & A B & 1,2 & B \\
\hline E. coli & 4,0 & A & 2,0 & A B & 1,3 & B & 4,5 & A & 3,2 & $\begin{array}{l}\mathrm{A} \\
\mathrm{B}\end{array}$ \\
\hline $\mathrm{DBO}_{5}$ & 4,1 & A & 1,5 & B & 1,8 & A B & 3,9 & A B & 4,1 & A \\
\hline
\end{tabular}


Os resultados obtidos da condutividade elétrica foram analisados estatisticamente em nível de 5\% (Tabela 2), e não apresentaram igualdade estatisticamente significativa entre os pontos de coleta. Aplicando-se o teste de comparações múltiplas (Bioestat 2), concluiu-se que para esta variável em nível estatístico: $\mathrm{P} 1 \neq \mathrm{P} 2, \mathrm{P} 1 \neq \mathrm{P} 3, \mathrm{P} 5 \neq \mathrm{P} 2$ e $\mathrm{P} 5 \neq \mathrm{P} 3$. Os resultados indicam que apesar da intensa atividade antrópica desta área, esta não foi ainda suficiente, até este momento, para acarretar grandes variações na condutividade da água nos pontos de coleta a jusante da área urbana do município de Santa Gertrudes - SP.

A condutividade elétrica não determina, especificamente, quais os íons que estão presentes nas águas, mas contribui para possíveis reconhecimentos de impactos ambientais na bacia de drenagem, ocasionados por diferentes fontes poluidoras (MATHEUS et al., 1995). À medida que mais sólidos dissolvidos são adicionados, a condutividade específica da água aumenta. Altos valores desta podem indicar características corrosivas da água (CETESB, 2001).

Os maiores valores de sólidos totais dissolvidos encontrados foram nos pontos P1 e P5 (Tabela 1), mesmo assim abaixo de $500 \mathrm{mg} \cdot \mathrm{L}^{-1}$, valor máximo permitido para corpos de água superficiais de classes 1,2 e 3 segundo a Resolução CONAMA 20/86 (CONAMA, 1986). Estes resultados foram analisados estatisticamente em nível de $5 \%$ quanto a igualdade entre todos os pontos de coleta. Aplicando-se o teste de comparações múltiplas (Bioestat 2), concluiu-se que para esta variável: $\mathrm{P} 1 \neq \mathrm{P} 2, \mathrm{P} 1 \neq \mathrm{P} 3$, $\mathrm{P} 5 \neq \mathrm{P} 2$ e $\mathrm{P} 5 \neq \mathrm{P} 3$ (Tabela 2 ).

Recomendações básicas sobre a concentração de sólidos totais dissolvidos são estabelecidas, principalmente, em relação ao sabor e palatabilidade. Valores = $500 \mathrm{mg} . \mathrm{L}^{-1}$ para sólidos totais dissolvidos são definidos para água destinada ao consumo humano (PALMA-SILVA, 1999).

Os valores de turbidez encontrados (Tabela 1) permitem classificar as águas dos pontos de coleta P1, e P3 na classe 1 e os demais na classe 2 . No ponto P4, no mês de agosto em decorrência a uma forte chuva no momento da coleta, o valor da turbidez excedeu a $100 \mathrm{UNT}$, mas os demais valores encontrados permitem enquadra-lo dentro da classe 2. Estes resultados analisados estatisticamente em nível de $5 \%$ rejeitaram a igualdade entre alguns pontos de coleta e concluiu-se que: $\mathrm{P} 4 \neq \mathrm{P} 3$ e $\mathrm{P} 2 \neq \mathrm{P} 3$ (Tabela 2).

Alta turbidez reduz a fotossíntese da vegetação submersa e algas, que por sua vez pode suprimir a produtividade de peixes. Logo, a turbidez influencia as comunidades biológicas aquáticas e afeta adversamente o uso doméstico, industrial e recreativo das águas (CETESB, 2001).

Os valores de alcalinidade encontrados (Tabela 1) demonstraram que os pontos de coleta P1, P4 e P5 mostraram valores muito altos, indicando elevado grau de 
poluição no ponto de confluência deste três pontos na sub-bacia do Ribeirão Claro. Estes resultados foram analisados estatisticamente em nível de $5 \%$ e observou-se que foram diferentes nos pontos de coleta, sendo que $\mathrm{P} 1 \neq \mathrm{P} 2, \mathrm{P} 2 \neq \mathrm{P} 5$ e $\mathrm{P} 3 \neq \mathrm{P} 5$. Este parâmetro representa a capacidade que o sistema aquoso tem de neutralizar e tamponar ácidos a ele adicionados (ESTEVES, 1988 citado por PALMA-SILVA, 1999).

Várias são as substâncias responsáveis pela alcalinidade da água, como silicatos, fosfatos de sais orgânicos, ácidos húmicos, embora os principais sejam os carbonatos, bicarbonatos e os hidróxidos. Este tipo de alcalinidade ocorre devido, principalmente, aos despejos industriais. Em águas superficiais, a alcalinidade também pode ser devida à presença de grandes quantidades de algas que removem $\mathrm{CO}_{2}$ da água pelo processo fotossintético, elevando o $\mathrm{pH}$ para 9 ou 10.

Os valores máximos e mínimos de oxigênio dissolvido (Tabela 1) mostraram que os pontos de coleta P1 e P4 tiveram pouca quantidade deste parâmetro, provavelmente, por receberem grande quantidade de matéria orgânica e resíduo industrial. Quando estes resultados foram analisados estatisticamente em nível de 5\%, observou-se que eles não foram iguais entre todos os pontos de coleta: $\mathrm{P} 2 \neq \mathrm{P} 4, \mathrm{P} 2 \neq \mathrm{P} 1, \mathrm{P} 3$ $\neq \mathrm{P} 4$ e $\mathrm{P} 3 \neq \mathrm{P} 1$.

Os pontos $\mathrm{P} 2$ e $\mathrm{P} 3$ tiveram condições iguais estatisticamente quanto aos valores de oxigênio dissolvido, porém em maio de 2002, os valores forem inferiores a 6,0 mg.L $\mathrm{L}^{-1}$. De acordo com a Resolução 20 (CONAMA, 1986), os pontos P2 se enquadra na classe 1 , com limite mínimo de $6 \mathrm{mg} . \mathrm{L}^{-1}$; o ponto P3 e P5 na classe 2, com limite mínimo de $5 \mathrm{mg} . \mathrm{L}^{-1}$ e os pontos $\mathrm{P} 4$ e $\mathrm{P} 1$, na classe 4 , pois a classe 3 possui para este parâmetro o limite mínimo de $4 \mathrm{mg} \cdot \mathrm{L}^{-} 1$, sendo que esses pontos apresentaram valores inferiores a esse limite.

Uma adequada provisão de oxigênio dissolvido é essencial para manutenção de processos de autodepuração em sistemas aquáticos naturais e indicam a capacidade das águas de manterem a vida aquática (CETESB, 1997). Através deste parâmetro é possível interpretar inúmeros fatores bióticos e abióticos, através das interações ecológicas como balanço entre produção (fotossíntese) e consumo do oxigênio (respiração) pela comunidade (MATHEUS et al., 1995).

Os valores de fósforo total observados estão na tabela 1. Estes foram analisados estatisticamente em nível de $5 \%$, observando-se a não igualdade entre os pontos de coleta, sendo que $\mathrm{P} 4 \neq \mathrm{P} 3, \mathrm{P} 5 \neq \mathrm{P} 3$ e $\mathrm{P} 1 \neq \mathrm{P} 3$ (Tabela 2 ). Altas concentrações de fosfatos na água estão associadas com a eutrofização acarretando o desenvolvimento de algas e outras plantas aquáticas desagradáveis em reservatórios de água parada (CETESB, 1997). Constatou-se que a microbacia do córrego São Joaquim não tem 
contribuído para o aporte de fósforo total na sub-bacia do Ribeirão Claro, pois os pontos P1 e P5 foram estatisticamente iguais e o P3 apresentou os menores valores deste parâmetro.

Os valores de nitrogênio orgânico total se encontram na tabela 1. Estes quando analisados estatisticamente em nível de 5\%, foram rejeitados em relação a igualdade entre os pontos de coletas: $\mathrm{P} 1 \neq \mathrm{P} 3$ e $\mathrm{P} 5 \neq \mathrm{P} 3$. O nitrogênio é um dos elementos mais importantes do metabolismo dos ecossistemas aquáticos, principalmente, pela formação de proteínas, constituintes da biomassa. Quando presente em baixas concentrações atua como fator limitante na produção primária dos ecossistemas aquáticos. Suas principais fontes podem ser material carreado pela chuva, material orgânico e inorgânico e fixação de nitrogênio molecular dentro do próprio sistema (PALMA-SILVA, 1999). Em grandes quantidades este componente, na forma de nitratos, acarreta a metemoglobinemia infantil (CETESB, 2001).

Os valores da cor aparente (Tabela 1) foram analisados estatisticamente em nível de 5\%, verificando-se igualdade estatisticamente significativa entre os pontos de coletas (Tabela 2). Relação entre a cor acentuada e o risco sanitário nas águas coradas tem sido pouco freqüente. O maior problema de coloração das águas, em geral, é estético por causar efeito repulsivo aos consumidores (CETESB, 2001).

Os resultados da DQO (Tabela 1) foram analisados estatisticamente em nível de $5 \%$, observando-se que foram rejeitados quanto a igualdade entre os pontos de coleta (Tabela 2), sendo que: P2 $\neq$ P5. Segundo a CETESB (2001) o acréscimo da concentração de DQO em um cor de água se deve principalmente aos despejos de origem industrial. Os maiores valores de DQO foram observados nos pontos de coletas situados no Ribeirão Claro.

Apesar de que para alguns dos parâmetros estudados, os resultados foram iguais estatisticamente entre os pontos de coletas, os maiores valores destes ocorreram naqueles localizados no Ribeirão Claro, P1 e P5. Esta constatação demonstra uma tendência para maior poluição deste rio, provavelmente, em decorrência da área urbana de Rio Claro.

Em relação aos resultados de sólidos totais em suspensão (Tabela 1), quando analisados estatisticamente em nível de 5\%, apresentaram igualdade entre os pontos de coleta (Tabela 2). Os efeitos dos sólidos em suspensão no ecossistema aquático variam em função, principalmente, da natureza dos sólidos, podendo ocasionar diversos tipos de impactos ambientais negativos como: prejuízo estético; interceptação da penetração da luz na água prejudicando a fotossíntese; efeito direto nas populações de peixes através do entupimento das brânquias e remoção do oxigênio dissolvido na água, quando estes são de natureza orgânica (MATHEUS et al., 1995). 
Os valores de salinidade encontram na tabela 1 e foram analisados estatisticamente em nível de 5\%. Verificou-se igualdade estatisticamente significativa entre os pontos de coleta (Tabela 2). Os problemas relacionados com a salinidade da água são decorrentes da concentração total dos sais minerais, sendo as águas superficiais em decorrência da evaporação e deposição de sais, aquelas que sofrem maior impacto. Os íons mais freqüentemente associados a esse parâmetro são cálcio, magnésio, sódio, bicarbonato, cloreto e sulfato, devido a maior solubilidade em água.

Os valores dos números mais prováveis (NMP) de coliformes totais estão na tabela 3 e foram analisados estatisticamente em nível de 5\% (Tabela 2). Houve rejeição da igualdade entre todos os pontos, concluindo-se que: $\mathrm{P} 1 \neq \mathrm{P} 3$. Os valores obtidos de Escherichia coli, (Tabela 4), também foram analisados estatisticamente em nível de $5 \%$ e foram rejeitados quanto a igualdade entre todos os pontos de coletas: $\mathrm{P} 1 \neq \mathrm{P} 3$ e $\mathrm{P} 4 \neq \mathrm{P} 3$ (Tabela 2).

Tabela 3. Valores do número mais provável (NMP) de coliformes totais (NMP/100mL) encontrados nos diferentes pontos de coleta, durante os meses de abr/2002 a set/2002.

\begin{tabular}{|c||c||c||c||c||c||}
\hline Meses & P1 & P2 & P3 & P4 & P5 \\
\hline \hline Abril & 198.630 & 24.192 & 24.192 & $>24.192$ & 61.310 \\
\hline \hline Maio & 32.550 & 3.448 & 2.481 & 64.880 & 8.330 \\
\hline \hline Junho & 1.119 .900 & 19.863 & 14.136 & 120.330 & 14.970 \\
\hline \hline Julho & $>241.920$ & 17.329 & 10.462 & 173.290 & 198.630 \\
\hline \hline Agosto & 1.990 & 2.247 & 1.723 & 6.520 & 34.480 \\
\hline \hline Setembro & $>241.920$ & 24.192 & 11.199 & $>241.920$ & $>241.920$ \\
\hline \hline
\end{tabular}

Tabela 4. Valores do número mais provável (NMP) de coliformes fecais (NMP/100mL) encontrados nos diferentes pontos de coleta, durante os meses de abr/2002 a set/2002.

\begin{tabular}{||c||c||c||c||c|c||}
\hline Meses & P1 & P2 & P3 & P4 & P5 \\
\hline \hline Abril & 260 & 59 & 156 & $>2.419$ & 548 \\
\hline \hline Maio & 2.230 & 20 & 10 & 3.950 & 1.750 \\
\hline \hline & & & & & \\
\hline
\end{tabular}




\begin{tabular}{||c||c||c||c||c||c||} 
Junho & 2.000 & 712 & 203 & 13.760 & 100 \\
\hline \hline Julho & $>241.920$ & 1.112 & 185 & 32.820 & 3.010 \\
\hline \hline Agosto & 100 & 50 & 20 & 300 & 740 \\
\hline \hline Setembro & $>241.920$ & 6.488 & 272 & 155.310 & 61.310 \\
\hline \hline
\end{tabular}

As bactérias do grupo coliforme são consideradas os principais indicadores de contaminação fecal, por estarem presentes em grande número no trato digestivo de animais de sangue quente e serem eliminadas com as fezes. Essas bactérias são usadas como principais indicadores para doenças de veiculação hídrica: febre tifóide, febre paratifóide, desinteria bacilar e cólera (PELCZAR et al., 1997). O uso de Escherichia coli para indicar poluição fecal mostra- se mais significativo do que o uso de coliformes total, por estarem restritas ao trato intestinal de animais de sangue quente (CETESB, 1997).

Segundo a Resolução 20 (CONAMA, 1986), todos os pontos de coleta podem ser enquadrados na classe 4, pois ultrapassaram o limite de 20.000 coliformes/100mL para classe 3 (Tabela 3 ). Os pontos P2 situou-se dentro da classe 3, pois seus valores não ultrapassaram este mesmo limite, mas em setembro foi acima do limite estabelecido para classe 2, ou seja, 5000 coliformes $/ 100 \mathrm{~mL}$. Esta mesma Resolução estabeleceu o limite máximo de Escherichia coli para as classes 1, 2 e 3, de 100 coliformesfecais $/ 100 \mathrm{~mL}, 1.000$ coliformes fecais $/ 100 \mathrm{~mL}$ e 4.000 coliformes fecais $/ 100 \mathrm{~mL}$, respectivamente. Os pontos P1, P4 e P5 (Tabela 4) ficaram enquadrados na classe 4, o ponto P2 na classe 3 e P3 na classe 2 .

Os resultados da $\mathrm{DBO}_{5}$, (Tabela 5) foram analisados estatisticamente em nível de $5 \%$ e foram rejeitados quanto a igualdade entre os pontos de coletas. Aplicandose o teste de comparações múltiplas (Bioestat 2), concluiu-se que: P2 $\neq$ P5 (Tabela 2). Este parâmetro representa a quantidade de oxigênio consumido durante um determinado tempo (CETESB, 1997).

Tabela 5. Valores da demanda bioquímica de oxigênio $\left(\mathrm{DBO}_{5}-\mathrm{mgO}_{2} \cdot \mathrm{L}^{-1}\right)$ nos diferentes pontos de coleta, durante os meses de abr/2002 a set/2002.

\begin{tabular}{||c||c||c||c||c|c||}
\hline Meses & P1 & P2 & P3 & P4 & P5 \\
\hline \hline Abril & 12,7 & 10,2 & 10,3 & 21,5 & 13,0 \\
\hline \hline Maio & 05,6 & 11,4 & 14,3 & 22,8 & 25,3 \\
\hline \hline
\end{tabular}




\begin{tabular}{||c||c||c||c||c||c||} 
Junho & 19,8 & 05,1 & 05,5 & 09,6 & 11,3 \\
\hline \hline Julho & 43,7 & 06,8 & 05,9 & 12,8 & 12,2 \\
\hline \hline Agosto & 09,4 & 03,6 & 04,1 & 10,7 & 15,3 \\
\hline \hline Setembro & 18,3 & 04,5 & 05,7 & 14,3 & 12,5 \\
\hline
\end{tabular}

Os maiores aumentos de $\mathrm{DBO}_{5}$ nas águas são acarretados por despejos de origem predominantemente orgânica. A presença de alto teor de matéria orgânica pode induzir à completa extinção do oxigênio e interferir no equilíbrio da vida aquática. Pelo fato da $\mathrm{DBO}_{5}$ somente medir a quantidade de oxigênio consumido, não indica a presença de matéria não biodegradável, nem leva em consideração o efeito tóxico ou inibidor dos materiais sobre a atividade microbiana (CETESB, 1997). Segundo a Resolução 20 (CONAMA, 1986), o limite máximo para os corpos hídricos de classe 3, é de 10 $\mathrm{mgO}_{2} \cdot \mathrm{L}^{-1}$ e para a classe 2 é de $5 \mathrm{mgO}_{2} \cdot \mathrm{L}^{-1}$, portanto, segundo este parâmetro os pontos P1, P4 e P5 podem ser enquadrados na classe 4 e os pontos P2 e P3 na classe 3.

\section{CONCLUSÕES}

De acordo com os parâmetros estudados, metodologia utilizada e o período de estudo, pode-se concluir:

1. Os trechos estudados dos córregos Ribeirão Claro e São Joaquim estão enquadrados na classe 4, segundo a Resolução 20 (CONAMA/86), quanto aos valores de oxigênio dissolvido, coliformes fecais e totais,

2. Os valores dos demais parâmetros estudados possibilitam o enquadramento desses corpos de água superficiais na classe 2 , de acordo com determinados parâmetros e segundo outros, dentro da classe 3 ;

3. Observou-se que a maior poluição desses dois córregos vem sendo acarretada pelo despejo do esgoto doméstico in natura, oriundo dos municípios de Rio Claro e Santa Gertrudes- SP.

\section{AGRADECIMENTOS}

Ao doutor José Silvio Govone pela ajuda nas análises estatísticas, a diretoria e funcionários do CEA, principalmente a Francisca Mattioli, à Sara Cristina Galvão por facilitar o trabalho de todos. Aos bolsistas e estagiários da Profa. Dra. Sâmia, Eduardo B. de Morais, André G. M. Bufon e Rodrigo C.M. Monteiro. 


\section{REFERÊNCIAS}

ABNT - Associação Brasileira de Normas e Técnicas, NBR 10004. Rio de Janeiro: ABNT, 1995.

AYRES, M.; AYRES JR., M.; AYRES, D.L.; SANTOS, A.A.S. BioEstat 2. São Paulo: CNPq, 2000.

BATALHA, B.L.; PARLATORE, A.C. Controle da qualidade da água para consumo humano. Bases conceituais e operacionais. São Paulo: CETESB, 1977.

BRAGA, A.C.O. Métodos Geo Elétricos Aplicados na Caracterização Geológica Formações Rio Claro e Corumbataí, no Município de Rio Claro-SP. Tese de Doutorado. Instituto de Geociências e Ciências Exatas: Universidade Estadual Paulista. Rio Claro, 1997. 169 p.

BRANCO, S.M. Água: origem uso e preservação. São Paulo: Moderna, 1993. p. 71.

BRINO, W.C. Contribuição à definição climática da Bacia do Corumbataí e Adjacências de Rio CLaro/SP, dando ênfase à caracterização dos tipos de tempo. Tese de Doutorado. Instituto de Geociências e Ciências Exatas: Universidade Estadual Paulista. Rio Claro, 1985. 119 p.

CETESB - Companhia de Tecnologia e Saneamento Ambiental. Guia de Coleta e Preservação de Amostras de Água. São Paulo, 1987. 150 p.

CETESB - Companhia de Tecnologia e Saneamento Ambiental. Relatório de Qualidade das Águas Interiores do Estado de São Paulo. São Paulo, 1997. 288 p.

CETESB - Companhia de Tecnologia e Saneamento Ambiental. Relatório de Qualidade das Águas Interiores do Estado de São Paulo. São Paulo, 2001. 224 p.

CHRISTOFOLETTI, S. R. Estudo Mineralógico, Químico e Textural das Rochas Sedimentares da Formação Corumbatai "jazida Cruzeiro", e suas Implicações nos Processos e Produtos Cerâmicos. Dissertação de Mestrado. Instituto de Geociências e Ciências Exatas: Universidade Estadual Paulista. Rio Claro, 1999.

CONAMA - Conselho Nacional do Meio Ambiente. Resolução CONAMA 20. Brasília: SEMA, 1986. 98 p.

CUNHA, L. V.; GONÇALVES, A. S.; FIGUEIREDO, V. A.; LINO, M. A Gestão da 
Água: Principios Fundamentais e Sua Aplicação em Portugal. Lisboa: Fundação Caloustre Gulbenkian, 1980.

CUNHA, M. A. A. Diagnóstico de Qualidade das Águas da Bacia do Ribeirão Claro $(S P)$. Dissertação de Mestrado. Instituto de Geociências e Ciências Exatas. Universidade Estadual Paulista. Rio Claro, 2000. 168 p.

EATON, A. D.; ClESCERI, L. S.; GREENBERG, A. E. Standart Methods for the Examination of Water and Wastewater. American Public Health Association, 1995.

FERREIRA, J. A. C. Projeto piloto de prevenção à poluição (P2) nas indústrias cerâmicas da região de Santa Gertrudes. Prevenção à poluição: Conceitos, técnicas a aplicabilidade. São Paulo: CETESB, 2000.

GOLTERMAN, H. L.; CLYMO, R. S.; OHNSTAND, M. A. Methods for Physical and Chemical Analysys of Freshwater. Oxford: Blackwell Scientific Publications International Program, 1978. 213 p.

IPT - INSTITUTO DE PESQUISA TECNOLÓGICA DO ESTADO DE SÃO PAULO. Mapa Geomorfológico do Estado de São Paulo. São Paulo, 1981.

LIMA, J. L. N. Hidroquímica pluvial e fluvial na bacia do rio Corumbataí (SP) e relações com o uso do Pb-210 como geocronômetro. Tese de Doutorado. Instituto de Geociências e Ciências Exatas: Universidade Estadual Paulista. Rio Claro, 2000. 260 p.

MACKERETH, F. J. H.; HERON, J.; TALlinG, J. F. Water Analysis: Some Revised Methods for Limnologists. Kendal: Titus \& Wilson, 1978. 117 p.

MATHEUS, C. E.; MORAIS, A. J.; TUNDISI, T. M.; TUNDISI, J. G. Manual de Análises Limnológicas. São Carlos: Centro de Recursos Hídricos e Ecologia Aplicada Escola de Engenharia de São Carlos: Departamento de Hidráulica e Saneamento. São Carlos, 1995. $62 \mathrm{p}$.

NEGRI, B. Urbanização e demanda de recursos hídricos na bacia do rio Piracicaba no estado de São Paulo. SEMANA DE DEBATES SOBRE RECURSOS HÍDRICOS E MEIO AMBIENTE. DAAE Consórcio Intermunicipal das Bacias dos Rios Piracicaba e Capivari, FUNDAP, 1992.

NOUR, E. A. A. Procedimentos de Análises Físico-químicas e Exames Microbiológicos para Águas de Abastecimento e Residuárias. Campinas: UNICAMP, 1994. 92 p.

PALMA-SILVA, G. M. Diagnóstico Ambiental, Qualidade da Água e Índice de Depuração do Rio Corumbatai - SP. Dissertação de Mestrado. Centro de Estudos 
Ambientais: Universidade Estadual Paulista. Rio Claro, 1999. 155 p.

PELCZAR JR., M. J.; CHAN, E. C. S.; KRIEG, N. R.; EDWARDS, D. D.; PELCZAR, M. F. Microbiologia: Conceitos e Aplicações. Makron Books do Brasil: São Paulo, 1997. 2a Ed. Vol. 2. 517 p.

RODRIGUES, R. Análise da dinâmica da cobertura vegetal e uso da terra na bacia do Ribeirão Claro, utilizando SIG e cadeia de Markov. Dissertação de Mestrado. Universidade Federal de São Carlos. São Carlos, 1997. 61 p.

THOMAZELLA, H. R. A influência do sazonamento nas características mineralógicas físico-químicas e tecnológicas das argilas para cerâmica vermelha na região de Rio Claro. Dissertação de Mestrado. Instituto de Geociências e Ciências Exatas: Universidade Estadual Paulista. Rio Claro, 1999.

ZAINE, J. E. Geologia da Formação Rio Claro na folha Rio Claro (São Paulo). Dissertação de Mestrado. Instituto de Geociências e Ciências Exatas: Universidade Estadual Paulista. Rio Claro, 1994.

ZAINE, J. E. Mapeamento Geológico-geotecnico por Método do Detalhamento Progressivo. Tese de Doutorado. Instituto de Geociências e Ciências Exatas: Universidade Estadual Paulista. 